\title{
Prevalence of low back pain in the community: implications for service provision in Bradford, UK
}

\author{
M Hillman, A Wright, G Rajaratnam, A Tennant, M A Chamberlain
}

\begin{abstract}
Study objective - To assist a purchasing district in the planning of services for low back pain by assessing the prevalence of symptoms and the current involvement of primary, secondary, and complementary care in the treatment of low back pain. In the light of these findings, to assess further the potential impact of a new system of open access to physical therapy, as recommended by the British Clinical Standards Advisory Group (CSAG).
\end{abstract}

Design - A two-stage cross sectional survey approach using postal questionnaires. Subjects - Altogether 1437 men and 1747 women aged 25-64 years, randomly selected from the family health services association register in Bradford.

Main results - An annual incidence of $4 \cdot 7 \%$ for low back pain was found, with lifetime, 12 month period, and point prevalences of $59 \%, 39 \%$, and $19 \%$ respectively. Over a one year period, $50.3 \%$ of episodes were acute ( $<2$ weeks), $21 \%$ were subacute ( 2 weeks -3 months), and $26 \%$ were chronic (over 3 months) in duration. Altogether $17.8 \%$ of the population in this age range experienced referred pain, numbness, or tingling, and $6.4 \%$ took time off work as a result of low back pain. In the same year, $20 \%$ of the population in the same age range consulted no-one about their pain, $13.7 \%$ were treated at the primary care level, $4 \%$ received secondary care, and $3 \%$ visited a complementary therapist. One fifth of those who did not consult a professional experienced severe pain during episodes. Prevalence estimates indicate that an emphasis on early intervention and primary care management of simple low back pain as recommended by the CSAG could generate a $131 \%$ surge in demand for physical therapy.

Rheumatology and Rehabilitation Research Unit, School of Medicine, Sniversity of Leeds,
Unool of Medicine, 36 Clarendon Road, Leeds LS2 9NZ

M Hillman

A Tennant

M A Chamberlain

Department of Public Health Medicine, Bradford Health Authority, Bradford A Wright

G Rajaratnam

Correspondence to: Ms M Hillman.

Accepted for publication January 1996 back pain has tripled to an estimated 106 million, ${ }^{2}$ and the number of patients referred to hospital has increased fivefold. ${ }^{3}$ At a total social cost to Britain of nearly $£ 6$ billion in 1993, the price of LBP continues to rise by an estimated $£ 500$ million each year. ${ }^{3}$

A recent British report issued by the Clinical Standards Advisory Group (CSAG) has recommended purchaser specific contracts for LBP, with an emphasis on primary care management of the problem. In particular, it recommends that general practitioners have open access to physical therapy. ${ }^{3}$ However, previous studies have demonstrated that regional differences exist in rates of general practice consultation for LBP. $^{4}$ If purchasers are to plan effectively and improve standards of care for those with LBP, local baseline estimates of need and current health care use are necessary. This study assesses the prevalence of LBP in a northern city in the UK. It identifies patterns of health seeking behaviour and explores the factors which influence the decision to consult. In doing so, it aims to assist purchasing districts in their evaluation of existing service provision for LBP. Furthermore, it considers future care provision in the light of the CSAG recommendations for the management of LBP.

\section{Methods \\ INSTRUMENTATION}

A two-phase postal questionnaire approach was taken. An initial screening questionnaire (phase 1) consisted of a set of enquiries about activities of daily living, and sought information on medical history, dependency, and employment status. Recipients were directed towards a mannikin which contained a shaded area between the lowest rib and the gluteal folds, ${ }^{5}$ and were asked, "Have you ever had back pain in the area shown below which lasted for more than a day?". Having excluded pain associated with menstruation, pregnancy, and feverish illness, those who answered positively were asked whether they had experienced pain in this area of the back during the past 12 months.

A more detailed questionnaire (phase 2) was then sent to all those who had reported low back pain during the previous year. This second questionnaire was designed as a tool which could be used periodically by purchasers to evaluate changes in the occurrence and impact of LBP. It thus concentrated mainly on LBP episodes which occurred during a period of 12 months before the study. This "snapshot" approach was also preferred for its potential to reduce problems relating to anamnesis, given that the quality of recollection of detail relating 
to a back pain episode diminishes over time. ${ }^{6}$ Phase 2 sought confirmation of the occurrence of low back pain as identified at phase 1 by asking respondents to indicate on a mannikin which parts of their back were painful. Respondents whose markings fell completely outside the area of interest were excluded from the study ( $6 \%$ of phase 2 responders). The eight-page phase 2 questionnaire investigated a variety of areas such as the perceived cause of back pain, the effect on employment, and patterns of consultation. Visual analogue scales were used as simple indicators of pain intensity ${ }^{78}$ and the Roland disability questionnaire ${ }^{910}$ measured functional status in those experiencing LBP on the day of completion.

Information from phases 1 and 2 contributed to estimates of incidence and prevalence for LBP. An estimate of lifetime prevalence was calculated and defined as the rate per 1000 of the population aged 25-64 who had ever had LBP which lasted for more than a day. Respondents who had experienced LBP in the 12 month period before the study contributed to estimates of 12 month period prevalence, while point prevalence estimates were generated based on those subjects who had LBP on the day of completion of phase 2. Subjects were also questioned for details of when they first experienced problems with their back. A one year incidence rate for the onset of new back problems was calculated based on numbers who stated that their back problems began during the 12 month period before the study.

Information regarding the duration of LBP episodes generated three subject groupings, namely the categories of acute, subacute, and chronic LBP. A great deal of variation exists in the timescales used by studies to define the transition from acute through subacute to chronic episodes of LBP. Given that most episodes of acute LBP settle within two weeks, ${ }^{11} 12$ this study set the threshold for entry into the subacute category at 15 days, while the chronic range encompassed subjects whose episodes of LBP were over 3 months in duration. ${ }^{13}$

The study was piloted on a sample of 502 patients aged 25-65, registered at a general practice in Bradford, West Yorkshire. Response rates of $74 \%$ and $72 \%$ were achieved for phases 1 and 2 respectively. Previous research has demonstrated a disparity between patient self reports and documented records of consultation for LBP. ${ }^{4}$ For validation purposes therefore, self reports of general practice consultation derived from the pilot study were checked against the subjects' own general practice records. Twenty six of the pilot subjects reported that their LBP had caused them to consult their general practitioner during the past year. Notes were available for 23 patients, and histories of consultation for LBP during the previous year were confirmed for $21(87 \%)$ of these. According to their patient notes, the remaining two subjects had consulted before the 12 month period specified. The practice notes of a sample $(n=45)$ of alleged nonconsulters were also checked, and contained six records of LBP consultation during the year in question. No age and sex differences emerged between subjects whose consultation histories were confirmed and those whose histories were uncorroborated. False positives $(13 \%)$ and false negatives (13\%) appeared to cancel each other out, thus alleviating the necessity to adjust the figures to account for bias in consultation estimates.

\section{POPULATION AND SAMPLE}

The Bradford Metropolitan District comprises approximately 476000 inhabitants of multiethnic and varied socioeconomic mix. ${ }^{14}$ The population register of the Family Health Services Association was used as a sampling frame from which an age stratified random sample was drawn. Bradford residents aged between 25-64 were selected (estimated population 240547 ) based on an estimated $7 \%$ one year incidence of LBP among those aged 25-34; 9\% for $35-44$ years; $5 \%$ for $45-54$ years, and $6 \%$ for $55-64$ years. $^{5}$

\section{RESPONSE AND BIAS}

The phase 1 screening questionnaire was posted in three waves, the initial posting and two further follow ups to non-responders. Altogether 3184 subjects responded (1437 men, 1747 women), representing a response rate of $76 \%$ of subjects whose addresses were known to be correct after validation against the electoral register. ${ }^{15}$ An investigation into potential bias included an assessment of the influence of age, sex, and low back pain on response to the phase 1 questionnaire. Overall prevalence estimates of LBP as indicated by phase 1 remained constant across the three response waves; indeed this unvarying pattern was sustained when prevalence rates were disaggregated according to age-sex groupings. The presence or absence of LBP among recipients did not therefore appear to bias their probability of response over time. ${ }^{16}$ A crude comparison of urban with suburban residents revealed no locality bias in terms of response to phase 1 or the prevalence of LBP.

Three postal waves of the phase 2 questionnaire yielded a valid response rate of $72 \%$, and phase 1 supplied information against which response bias at phase 2 could be assessed (for example, reported level of dependency). Once again, no evidence of bias was detected and the data were weighted for non-response by age and sex alone.

The $95 \%$ confidence intervals for prevalence estimates were calculated according to Schoenberg's method, ${ }^{17}$ and significant differences in these estimates were identified by non-overlapping confidence intervals. Non-parametric tests were carried out during data analysis using the Statistical Package for the Social Sciences (SPSSPC) software.

\section{Results}

INCIDENCE AND PREVALENCE

The annual incidence rate for the onset of back problems was found to be 47 per 1000 (CI: $38,58 / 1000)$, with a rate of $40 \cdot 5$ per 1000 (CI: 
Table 1 Age-sex specific estimates of prevalence for low back pain amongst a population aged 25-64. Expressed as rate per 1000 with 95\% confidence intervals (95\% CI)

\begin{tabular}{|c|c|c|c|}
\hline Age (y) & Men $(95 \% C I)$ & Women $(95 \%$ CI) & Total (95\% CI) \\
\hline $\begin{array}{l}\text { Lifetime } \\
25-34 \\
35-44 \\
45-54 \\
55-64\end{array}$ & $\begin{array}{l}\text { evalence } \\
541 \cdot 32(482 \cdot 86,606 \cdot 82) \\
636 \cdot 02(567 \cdot 33,712 \cdot 98) \\
620 \cdot 33(538 \cdot 45,714 \cdot 00) \\
663.97(576 \cdot 32,764 \cdot 23)\end{array}$ & $\begin{array}{l}472 \cdot 86(417 \cdot 06,536 \cdot 22) \\
555 \cdot 60(490 \cdot 04,630 \cdot 05) \\
640 \cdot 86(556 \cdot 27,737 \cdot 63) \\
664 \cdot 41(576 \cdot 71,764 \cdot 74)\end{array}$ & $\begin{array}{l}507 \cdot 64(464 \cdot 49,554 \cdot 85) \\
597 \cdot 27(546 \cdot 50,652 \cdot 81) \\
630 \cdot 42(574 \cdot 32,692 \cdot 20) \\
664 \cdot 19(601 \cdot 76,733 \cdot 27)\end{array}$ \\
\hline Total & $607 \cdot 35(570 \cdot 30,646 \cdot 22)$ & $569 \cdot 08(532 \cdot 66,607 \cdot 78)$ & $588 \cdot 52(566 \cdot 22,610 \cdot 82)$ \\
\hline $\begin{array}{l}12 \text { mont } \\
25-34 \\
35-44 \\
45-54 \\
55-64\end{array}$ & $\begin{array}{l}\text { prevalence } \\
368 \cdot 58(306 \cdot 29,443 \cdot 03) \\
410 \cdot 48(339 \cdot 47,495 \cdot 86) \\
385 \cdot 78(307 \cdot 85,478 \cdot 37) \\
373 \cdot 75(290 \cdot 41,474 \cdot 67)\end{array}$ & $\begin{array}{l}348 \cdot 65(287 \cdot 29,422 \cdot 57) \\
403 \cdot 25(330 \cdot 66,491 \cdot 15) \\
452 \cdot 31(366 \cdot 38,551 \cdot 82) \\
409 \cdot 52(323 \cdot 11,511 \cdot 91)\end{array}$ & $\begin{array}{l}358 \cdot 78(316 \cdot 44,406 \cdot 85) \\
406.99(353 \cdot 27,468 \cdot 45) \\
418.49(360 \cdot 74,485 \cdot 45) \\
391.91(331.95,462 \cdot 46)\end{array}$ \\
\hline Total & $384 \cdot 86(348 \cdot 68,424 \cdot 88)$ & $397 \cdot 73(360 \cdot 34,439 \cdot 09)$ & $391 \cdot 19(363 \cdot 81,420 \cdot 53)$ \\
\hline $\begin{array}{l}\text { Point pre } \\
25-34 \\
35-44 \\
45-54 \\
55-64\end{array}$ & $\begin{array}{l}\text { alence } \\
190 \cdot 05(145 \cdot 39,243 \cdot 26) \\
156 \cdot 09(113 \cdot 01,210 \cdot 73) \\
185 \cdot 91(133 \cdot 48,252 \cdot 83) \\
190 \cdot 84(133 \cdot 01,265 \cdot 26)\end{array}$ & $\begin{array}{l}130 \cdot 74(93 \cdot 35,177 \cdot 80) \\
211 \cdot 40(158 \cdot 76,274 \cdot 82) \\
253 \cdot 64(190 \cdot 48,329 \cdot 73) \\
238 \cdot 36(173 \cdot 77,319 \cdot 41)\end{array}$ & $\begin{array}{l}160 \cdot 87(131 \cdot 75,196 \cdot 26) \\
182 \cdot 74(148 \cdot 20,222 \cdot 95) \\
219 \cdot 21(177 \cdot 12,267 \cdot 43) \\
214 \cdot 99(170 \cdot 49,266 \cdot 59)\end{array}$ \\
\hline Total & $179.94(154.92,208 \cdot 73)$ & $200 \cdot 09(173 \cdot 28,231 \cdot 10)$ & $189.85(172 \cdot 01,209 \cdot 60)$ \\
\hline
\end{tabular}

Table 2 Age-sex specific estimates of disability caused by low back pain. Mean scores on a single day as measured by the Roland disability questionnaire (maximum score 24)

\begin{tabular}{llll}
\hline Age $(y)$ & Men $(95 \% C I)$ & Women $(95 \% C I)$ & Total $(95 \% C I)$ \\
\hline $25-34$ & $4 \cdot 4(3 \cdot 4,5 \cdot 7)$ & $4 \cdot 3(3 \cdot 0,5 \cdot 8)$ & $4 \cdot 4(3 \cdot 6,5 \cdot 3)$ \\
$35-44$ & $4 \cdot 8(3 \cdot 5,6 \cdot 5)$ & $5 \cdot 6(4 \cdot 2,7 \cdot 2)$ & $5 \cdot 2(4 \cdot 2,6 \cdot 4)$ \\
$45-54$ & $4 \cdot 6(3 \cdot 3,6 \cdot 3)$ & $5 \cdot 3(4 \cdot 0,7 \cdot 0)$ & $5 \cdot 0(4 \cdot 0,6 \cdot 0)$ \\
$55-64$ & $7 \cdot 8(5 \cdot 5,11 \cdot 0)$ & $6 \cdot 7(5 \cdot 0,9 \cdot 0)$ & $7 \cdot 2(5 \cdot 7,8 \cdot 9)$ \\
Total & $5 \cdot 2(4 \cdot 5,6 \cdot 0)$ & $5 \cdot 5(4 \cdot 7,6 \cdot 3)$ & $5 \cdot 4(4 \cdot 9,5 \cdot 9)$ \\
\hline
\end{tabular}

29, 55/1000) for men and 54 per 1000 (CI: $40,71 / 1000$ ) for women.

Table 1 shows lifetime, 12 month period, and point prevalence rates according to age and sex. As expected, the cumulative lifetime prevalence of LBP (59\%) showed a general upward trend with age, with the youngest age group (25-34 years old) showing a significantly lower lifetime prevalence than that in the 45-64 age range. The 12 month period prevalence rate for LBP was $39 \%$, and although women report a higher period prevalence than men in the over $45 \mathrm{~s}$, overlapping confidence intervals rule out significant differences between the sexes. On a single day, the (point) prevalence of LBP was $19 \%$. Point prevalence rates amongst the male population remained roughly constant across age ranges; however, the rates for women showed some fluctuations, with significantly lower prevalence rates occurring amongst those aged 25-34.

\section{DURATION}

Approximately half $(50.3 \%)$ of subjects reporting LBP during the previous year described episodes which were acute in duration $(<2$ weeks). Just over a fifth $(21 \cdot 0 \%)$ fell into the subacute category having had some back pain most days for between 2 weeks and 3 months, whilst over a quarter $(26.0 \%)$ were classified as chronic sufferers in that they experienced LBP on most days for over 3 months. (Due to missing data, information on episode duration was unavailable for a further $2 \cdot 7 \%$ of those who experienced episodes of LBP.) In population terms, an estimated $19 \cdot 7 \%$ (CI: $17 \cdot 8 \%, 21 \cdot 7 \%$ ) of those aged 25 to 64 experienced acute, $8.2 \%$ subacute (CI: $7 \cdot 0 \%, 9.6 \%$ ), and $10.2 \%$ (CI: $8 \cdot 8 \%, 11 \cdot 7 \%$ ) chronic episodes of LBP over a
12 month period. No sex differences in prevalence emerged within duration groups, however chronic back pain did appear to be significantly more prevalent amongst the 45-54 year old age group $(14 \% \mathrm{CI}: 10.7,18 \cdot 1)$ than amongst the younger (25-44) age range. For $62 \cdot 2 \%$ of those with chronic LBP and $51 \cdot 8 \%$ of all phase 2 responders, LBP was a long standing problem with a history of five or more years.

\section{PAIN AND DISABILITY}

Using a visual analogue scale, subjects described the intensity of pain reached during the previous year when their backs were at their most uncomfortable. On a scale of 1 to 10 , subjects reported a mean pain score of $6 \cdot 24$. "Mild" pain ranging between 1-4 on the scale was reported by $26.5 \%$, "moderate pain" (range $5-7$ ) by $40 \cdot 8 \%$, and "severe pain" (range $8-10$ ) by $32.6 \%$ of those with LBP. Levels of pain showed a pattern of increase according to duration of the episodes. Those with acute episodes reported significantly lower levels of pain than those with subacute or chronic LBP (Mann-Whitney $\mathrm{p}<0.01$ ).

Symptoms of referred pain, numbness, or tingling spreading to the legs were also present amongst $45 \cdot 6 \%$ of subjects who reported LBP during the previous year; the equivalent of $17 \cdot 8 \%$ of the population aged $25-64$.

Altogether $48 \cdot 5 \%$ of subjects who had experienced LBP at some time during the previous year also reported LBP on the day of the study. For this group of subjects, measurements on a second visual analogue scale indicated a mean pain score of 4.25 on the day of the study, as compared to a mean pain score of 6.74 at a time during the previous year when their LBP was at its most uncomfortable (Wilcoxen $\mathrm{p}<0.01$ ). These subjects also averaged a mean score of 5.4 (out of a possible 24) on the Roland disability questionnaire, and table 2 shows age by sex population means for disability caused by LBP. Those aged 55-64 years experience significantly higher levels of disability than those aged 25-34; however, no other age or sex differences in disability were detected. It is important to note that very few people with LBP on the day of the study were without some limitation. Only $4.5 \%$ experienced no disability whilst $64.4 \%$ scored between 1 and 6 points; 22.7 between 7 and 12 points; and $8.4 \%$ scored 13 points or over. Table 3 lists those items on the Roland disability questionnaire most frequently chosen by subjects experiencing LBP on the day of the study. The wide ranging impact of LBP was indicated by the fact that almost half of those with LBP on a single day experienced sleep disturbance, and a third reported that they were more irritable and bad tempered than usual.

\section{EMPLOYMENT}

An examination of the beliefs of respondents concerning the cause of their LBP revealed that over a third (35\%) attributed this to the nature of their job or to a work related accident. In 
Table 3 Roland disability questionnaire: most frequent problems experienced or behaviours adopted as a result of low back pain. Includes only subjects experiencing low back pain on the day of the study

\begin{tabular}{llc}
\hline & $\begin{array}{l}\text { \% of those with low } \\
\text { back pain "today" }\end{array}$ & $\begin{array}{c}\text { Population prevalence } \\
\text { per 1000 }\end{array}$ \\
\hline $\begin{array}{l}\text { Change position frequently to try and get back } \\
\text { comfortable }\end{array}$ & 72 & $130 \cdot 7(88 \cdot 7,185 \cdot 6)$ \\
Sleep less well because of back & 47 & $84 \cdot 9(72 \cdot 7,99)$ \\
Avoid heavy jobs around the house & 38 & $69 \cdot 5(58 \cdot 5,82 \cdot 5)$ \\
Back is painful almost all the time & 33 & $59 \cdot 3(49 \cdot 2,71 \cdot 4)$ \\
Try not to bend or kneel & 32 & $58 \cdot 0(48 \cdot 1,70 \cdot 0)$ \\
More irritable and bad tempered than usual & 32 & $57 \cdot 1(47 \cdot 3,69 \cdot 0)$ \\
Only stand for short periods & 30 & $54 \cdot 7(45 \cdot 1,66 \cdot 4)$ \\
Difficult to turn over in bed & 29 & $53 \cdot 2(43 \cdot 7,64 \cdot 7)$ \\
Trouble putting on socks & 29 & $51 \cdot 9(42 \cdot 6,63 \cdot 3)$ \\
Lie down to rest more often & 27 & $49 \cdot 5(40 \cdot 2,60 \cdot 4)$ \\
\hline
\end{tabular}

Table 4 Prevalence rates for consultation with professionals/services about low back pain and the proportion of low back pain sufferers who consult

\begin{tabular}{lccc}
\hline & $\begin{array}{l}\text { Estimated }^{*} \\
\text { no }\end{array}$ & $\begin{array}{c}\text { \% with low } \\
\text { back pain }\end{array}$ & Prevalence per 1000 \\
\hline General practitioner & 34541 & $36 \cdot 7$ & $143 \cdot 6(128 \cdot 1,161 \cdot 0)$ \\
Hospital doctort & 9198 & $9 \cdot 8$ & $38 \cdot 2(30 \cdot 1,47 \cdot 8)$ \\
Work doctor & 2011 & $2 \cdot 1$ & $8 \cdot 4(4 \cdot 8,13 \cdot 5)$ \\
Pharmacist & 10421 & $11 \cdot 1$ & $43 \cdot 3(34 \cdot 6,53 \cdot 7)$ \\
Physiotherapist & 9268 & $9 \cdot 8$ & $38 \cdot 5(30 \cdot 3,48 \cdot 2)$ \\
Osteopath & 4237 & $4 \cdot 5$ & $17 \cdot 6(12 \cdot 2,24 \cdot 7)$ \\
Chiropractor & 1098 & $1 \cdot 2$ & $4 \cdot 6(2 \cdot 1,8 \cdot 7)$ \\
Acupuncturist & 1219 & $1 \cdot 3$ & $5 \cdot 1(2 \cdot 4,9 \cdot 3)$ \\
Pain clinic & 1006 & $1 \cdot 1$ & $4 \cdot 2(1 \cdot 8,8 \cdot 2)$ \\
Casualty & 1723 & $1 \cdot 8$ & $7 \cdot 2(3 \cdot 9,12 \cdot 0)$ \\
Back $x$ ray & 8381 & $8 \cdot 9$ & $34 \cdot 8(27 \cdot 1,44 \cdot 3)$ \\
\hline
\end{tabular}

* Figures are weighted to represent estimates for Bradford

† Includes doctors seen at casualty departments and pain clinics. Base $=94100$.

Table 5 Involvement of primary, secondary, and complementary care in the treatment of low back pain

\begin{tabular}{llcc}
\hline & $\begin{array}{l}\text { Estimated }^{*} \\
\text { no }\end{array}$ & $\begin{array}{l}\text { \% with low } \\
\text { back pain }\end{array}$ & Prevalence per 1000 \\
\hline No involvement & 48255 & $51 \cdot 3$ & $200 \cdot 6(181 \cdot 7,221 \cdot 5)$ \\
General practitioner (GP) only & 16820 & $17 \cdot 9$ & $69 \cdot 9(58 \cdot 9,82 \cdot 9)$ \\
Primary care onlyt & 29820 & $31 \cdot 7$ & $124 \cdot 0(109 \cdot 3,140 \cdot 6)$ \\
Secondary care (no complementary $\ddagger)$ & 7804 & $8 \cdot 3$ & $32 \cdot 4(25 \cdot 0,41 \cdot 5)$ \\
Complementary only & 2639 & $2 \cdot 8$ & $11 \cdot 0(6 \cdot 9,16 \cdot 6)$ \\
Primary and complementary & 3193 & $3 \cdot 3$ & $13 \cdot 3(8 \cdot 7,19 \cdot 5)$ \\
Secondary and complementary & 1834 & 1.9 & $7 \cdot 6(4 \cdot 3,12 \cdot 6)$ \\
Workplace doctor/nurse only $§$ & 555 & $0 \cdot 6$ & $2 \cdot 3(0 \cdot 8,5 \cdot 4)$ \\
Total (excluding GP only) & 94100 & 100 & $391 \cdot 2(363 \cdot 8,420 \cdot 5)$ \\
\hline
\end{tabular}

* Figures are weighted to represent estimates for Bradford.

+ Primary care only includes consultation with a general practitioner, and/or pharmacist or physiotherapist where secondary care is not involved; $4 \%$ of this group consulted a pharmacist exclusively.

$\mp$ Complementary care includes consultation with an osteopath, chiropractor, acupuncturist, or any other alternative therapist.

Excludes $1.5 \%$ of subjects with low back pain who visited a workplace doctor or nurse in addition to other listed professionals.

other words, during a 12 month period an estimated $13 \cdot 7 \%$ of the Bradford population between the ages 25-64 experienced LBP which they believed was caused by their job. Work related causes were significantly more prevalent amongst males of this population $(16.8 \%)$ than amongst females $(10 \cdot 6 \%)$.

In the 12 months prior to the study $21.8 \%$ of employed people with LBP took time off work as a result of problems with their back, representing a prevalence rate of $6.4 \%(\mathrm{CI}$ : $5 \cdot 4,7 \cdot 7)$ of all adults aged 25-64. Population estimates for sickness absence followed a pattern of decline with increasing age.

PATTERNS OF HEALTH CARE

Estimates of prevalence, duration, and severity are useful indicators of the widespread nature of LBP; however, if purchasers are to identify areas of unmet need, these figures must be viewed alongside current trends in health seeking behaviour. Table 4 provides details of contact with individual LBP professionals or agencies, and expresses these contacts as a prevalence per 1000 people. For example, over a 12 month period, 143.6 per 1000 of the 25-64 year old population consulted their GP about LBP, and an estimated 38.2 per 1000 consulted a hospital doctor.

Table 5 lists the relative involvement of primary, secondary, and complementary care in the treatment of LBP. Over a period of 12 months, $51.3 \%$ of those with LBP consulted no-one about their pain episodes (prevalence 201 per 1000 CI: 182, 222). Amongst those who consulted a professional about their LBP (prevalence 191 per $1000 \mathrm{CI}: 171,212$ ), most were treated at the primary care level (prevalence 137 per 1000 CI: 121, 156). Just over a fifth $(21 \%)$ of consulters received secondary care, a figure which includes both state funded and private consultation. When visits to a casualty department were excluded from the category of secondary care, an estimated $8.6 \%$ of all those who consulted their general practitioner for LBP also saw a hospital doctor, implying a $21.6 \%$ referral rate amongst patients with LBP (prevalence 30 per 1000 CI: 23, 39) from general practitioners.

In a single year, $8 \%$ of those experiencing LBP consulted a complementary therapist that is, an osteopath, chiropractor, or other alternative therapist (prevalence 32 per 1000 CI: 24,41$)$. Altogether $2 \cdot 8 \%$ of those with LBP did so to the exclusion of conventional care, the equivalent of $5 \cdot 8 \%$ of all consulters. It is not known to what extent this small group of patients sought primary or secondary care outside the threshold of the study period.

What factors affect an individual's decision to consult? The longer the duration of LBP episodes, the greater the likelihood of consultation. Indeed those with acute LBP were significantly less likely to consult a professional about their back pain than those who experienced subacute or chronic episodes $\left(\chi^{2}\right.$ $31 \cdot 6 ; \mathrm{p}<0 \cdot 01)$.

Consulters reported higher levels of pain during episodes than non-consulters (MannWhitney $p<0.01$ ) and greater mean disability on the day of the study as measured by the Roland disability questionnaire (Mann-Whitney $\mathrm{p}<0.01$ ). Nevertheless, $43 \%$ of those reporting some disability on the day of the study had not consulted a professional during the previous year, and one fifth of non-consulters described levels of pain which were severe (prevalence 38 per $1000 \mathrm{CI}: 30,48)$. About one in eight $(13 \%)$ of non-consulters experienced chronic episodes with moderate to severe pain. Exploratory stepwise logistic regression models indicated that consulters were 2.5 (CI: $0 \cdot 14$, $4 \cdot 83$ ) times more likely to experience severe pain than non-consulters. They were 1.8 times as likely to report both episodes which were over 2 weeks in duration (CI: $0 \cdot 46,4 \cdot 14$ ) and some form of comorbidity (CI: $0.54,4.11$ ), and $5.9(\mathrm{CI}: 3.4,8.5)$ times more likely to take time off work than non-consulters. The effects 
of all these contributing factors were adjusted for each other. In population terms, the necessity to take time off work was significantly associated with consultation, given that the confidence intervals for this factor did not overlap $1 \cdot 00$. Indeed $85 \%$ of subjects who took time off work as a result of back pain consulted one or more professionals. Whether time off work is a cause or consequence of consultation cannot be addressed by the current study. The confusion in causality extends to the use of complementary therapies, where the relationship with sick leave is an inverse one. The majority (64\%) of employed subjects who sought complementary care did not take time off work, although consulters of complementary therapy did report significantly higher levels of pain than non-consulters (Mann-Whitney $\mathrm{p}<0.01$ ).

A comparison between primary and secondary health care users showed that those who graduated into secondary care were more likely to experience chronic episodes $\left(\chi^{2} 28.9\right.$; $\mathrm{p}<0.01)$, time off work $\left(\chi^{2} 14.2 ; \mathrm{p}<0.01\right)$, and higher levels of pain (Mann-Whitney $p<0 \cdot 01$ ). Primary and secondary care users did not differ in the characteristics of age, sex, or disability on the day of the study.

\section{Discussion}

Overall lifetime, yearly, and point prevalence estimates concord well with previous population studies of LBP. ${ }^{4518} \mathrm{~A}$ snapshot of a single day reveals that an estimated $19 \%$ of those aged 25-64 experience LBP. The vast majority of these will describe symptoms which are severe enough to have some disabling impact, and one third will indicate that their back is painful almost all of the time.

Most striking is the high rate of referral to secondary care amongst the study population, although the appropriateness of these referrals was not known and merits further investigation. The extensive use of hospital specialist facilities contrasts with the somewhat limited use of complementary therapies. The small numbers involved restricts us to superficial analysis of the characteristics of complementary therapy users. Patient attitude and expectation, socioeconomic status, and therapist availability may combine with factors stated earlier to influence uptake in complementary care.

This study estimates that $14 \%$ (CI: $12 \%$, $16 \%$ ) of adults aged 25-64 consult their GP for LBP. Traditionally, population studies of LBP give rise to rates of general practice consultation which are higher than those derived from the study of medical records. This study is no exception. The third national morbidity study estimates that $7 \cdot 5 \%-9 \%$ of adults of a comparable age range consult a GP in a single year. ${ }^{19}$ It has been suggested that the disparity between general practice records and patient recall may be due to differing perceptions of symptom priority or of the reasons for consultation, particularly in patients presenting with comorbid conditions. It has been further suggested that whilst medical records may provide useful estimates of current health care consumption, it is likely that population studies better estimate total health care need as perceived by the public. ${ }^{2}$

Medical records suggest that each general practitioner has an estimated 400 consultations for back pain per year. ${ }^{2}$ Despite this, the current study shows that $63 \%$ of LBP sufferers chose not to consult their general practitioner, and half consulted no-one. The existence of a subset of non-consulters who described severe pain suggests that current figures underestimate the potential prevalence pool for consultation. The majority $(62 \%)$ of non-consulters experienced episodes lasting for less than 2 weeks; however, the recurrent nature of $\mathrm{LBP}^{2021}$ guards against dismissal of this group of current non-consulters to the ranks of never consulters. Evidence that half of those who experience LBP are silent about their pain, highlights the need to assess the appropriateness of self treatments adopted by the public and the efficacy of public education messages on the self management of pain episodes.

Given the close association between consultation and work loss, and the contribution of work related incidents to the alleged causes of LBP, collaboration between employers, health care purchasers, and providers in the prevention and rehabilitation of LBP may prove mutually beneficial. One example of such collaboration might be the establishment of a programme of early, gradual, and biomechanically controlled return to work. ${ }^{22}$ At present no formal mechanism for such cooperation exists in this country. ${ }^{23}$

Over a third of those with LBP attribute the cause of their episodes to their job or to a work related accident, and almost two fifths (39\%) of these people are treated at the primary care level only. Thus, $14 \%$ of all those with LBP are treated by primary health care for what they perceive to be work related LBP. If employers were to develop occupational health programmes in order to take responsibility for the prevention or treatment of this group of consulting workers with job related LBP, we estimate that the demand placed on the primary health care system would reduce by $34 \%$. An alternative approach might be for employers to substitute appropriate health care for all employees who currently take time off work and consult primary care professionals for LBP. Under these circumstances, primary care involvement in the treatment of LBP could reduce by $25 \%$. By assuming responsibility for the treatment of employees who either take time off work or attribute work related causes to their LBP, or both, employers could reduce the burden of LBP on primary care by as much as $49 \%$. Naturally, not all employers have access to occupational health facilities; however, existing occupational health services could potentially take up at least part of the projected estimate of demand. Experimental occupational health cooperatives could be established to service smaller businesses, thereby offering wider occupational health coverage to the working population.

The CSAG emphasises early intervention in the treatment of LBP and recommends that 
general practitioners have direct access to physical therapy, namely physiotherapy, chiropractic, and osteopathy for the treatment of simple backache. This study found that, in one year, $14.2 \%$ of those with LBP, or 55.4 (CI: $45 \cdot 7,67 \cdot 1)$ per 1000 of the population aged 25-64, received some form of physical therapy, whether privately or state funded. In the same year, $23.3 \%$ of those experiencing LBP episodes lasting 2 weeks or more received treatment solely from their general practitioner. If general practitioners were to capitalise on direct access to physical therapy for this latter group of patients, namely subacute and chronic LBP sufferers receiving no other treatment, the potential demand for physical therapy amongst those aged $25-64$ would increase by $77 \%$ or $42 \cdot 8$ (CI: $34 \cdot 1,53 \cdot 0$ ) per 1000 .

The CSAG also emphasises the importance of primary care management of simple low back pain, and recommends a redirection of LBP patients away from secondary care. Referral to secondary care is a complex process and reasons for the variability in referral rates amongst general practitioners remain unclear. ${ }^{24}$ Nevertheless, this study estimates that if general practitioners were to seek alternatives to specialist referral for patients who have no serious spinal or neurological pathology, the demand for physical therapy could lead to a potential additional increase of $54 \%$ or 30 (CI: 23,39 ) per 1000 . Thus, a desirable reduction in secondary referral, in combination with open access to physiotherapists, chiropractors, and osteopaths could have the cumulative effect of boosting demand for physical therapy by $131 \%$, from a current 55.4 per 1000 to a maximum of $128 \cdot 2$ per 1000 of the population aged 25-64. This total excludes those with acute LBP who consult their general practitioner exclusively $(27 \cdot 2$ per 1000 CI: $20 \cdot 3,35 \cdot 6$ ), a proportion of whom may also benefit from physical therapy. It may further underestimate demand by omitting an unknown quantity of current non-consulters whose interest will be aroused by the availability of state funded "alternative" therapies.

It is clear from the above estimates that open access to physical therapy may generate a substantial demand for this service. A crisis of availability may result unless the magnitude of potential demand is understood, and funding for adequate numbers of therapists is made available. In addition, GP fundholders and other primary health care purchasers may wish to be convinced of the efficacy of physical therapies in the management of LBP before diverting purchasing funds away from secondary care.

\section{CONCLUSION}

A simple questionnaire approach has been used to assess the nature and prevalence of LBP, and to estimate current and potential service uptake. The implications of open access to physical therapy, as recommended by the CSAG, were evaluated. Even if general practitioners were to restrict their referrals for physical therapy to patients with subacute or chronic LBP, the demand for physiotherapy, osteo- pathy, and chiropractic could more than double. Purchasing authorities should assess demand at the local level and allocate sufficient resources for the recruitment of physical therapists. Furthermore, purchasers of health care might consider using population studies to observe the effects of service reorganisation on patterns of consultation, referral, and ultimately prevalence of LBP.

Health professionals are consulted by only half of those who experience LBP, and a fifth of non-consulters experience severe pain. In one year, LBP also results in sickness absence for over a fifth of those who are employed. Future research might investigate the appropriateness of self treatments adopted, the effectiveness of public education messages on the management of LBP, and the impact on sickness absence of interventions in the workplace.

With thanks to Dr Neil Bowring and partners of Howarth Road Health Centre, Bradford for permission to involve their patients in the pilot study and to Dr Philip Helliwell for his useful in the pilot

1 Waddell G. A new clinical model for the treatment of low back pain. Spine 1987;12:632-44.

2 Clinical Standards Advisory Group. Epidemiology review: the epidemiology and cost of back pain. London: HMSO, May 1994.

3 Clinical Standards Advisory Group, Back pain: report of a CSAG committee on back pain. London: HMSO, May 1994

4 Walsh K, Cruddas M, Coggon D. Low back pain in eight areas of Britain. $\mathcal{F}$ Epidemiol Community Health 1992;46: 227-30.

5 Mason V. The prevalence of back pain in Great Britain. A report prepared for the Department of Health by the Office of Population Censuses and Surveys Social Survey Division, based on the OPCS Omnibus Survey March, April, June 1993. London: HMSO, 1994.

6 Walsh K, Coggon D. Reproducibility of histories of low back pain obtained by self administered questionnaire. Spine 1991;16:1075-7.

7 Frymoyer et al. Clinical tests applicable to the study of chronic low back disability. Spine 1991;16:68.

8 Waddell G. Clinical assessment of lumbar impairment. Clin Orthop 1987;221:110-20.

9 Roland M, Morris R. A study of the natural history of back pain. Part 1: Development of a reliable and sensitive measure of disability in low back pain. Spine 1983;8: 141-4.

10 Deyo RA. Comparative validity of the sickness impact profile and shorter scales for functional assessment in low back pain. Spine 1986;11:951-4.

11 Franks A. Low back pain. BMF 1993;306:901-9.

12 Coste J, Delecoeuillerie G, Cohen de Lara A, Le Parc JM, Paolaggi JB. Clinical course and prognostic factors in acute low back pain: an inception cohort study in primary care practice. $B M \mp$ 1994;308:577-80.

13 Waddell G, Bircher M, Finlayson D, Main CJ. Symptoms and signs: physical disease or illness behaviour. BMF 1984; 289:739-41.

14 Yorkshire Health Authority. Public Health Report. A census based view of the population and its health: statistical review.

15 Bickler G, Sutton S. Inaccuracy of FHSA registers: help from electoral registers. $B M \mathcal{F}$ 1993;306:1167.

16 Tennant A, Badley EM. A confidence interval approach to investigating non-response bias and monitoring response to postal questionnaires. $\mathcal{f}$ Epidemiol Community Health 1991;45:81-5.

17 Schoenberg BS. Calculating confidence intervals for rates and ratios. Simplified method utilizing tabular values based on the poisson distribution. Neuroepidemiology 1983; 2:257-65.

18 Dunnell K, Cartwright A. Medicine takers, prescribers and hoarders. London: Routledge and Kegan, 1972.

19 Royal College of General Practitioners. Morbidity statistics from general practice; third national morbidity survey 1981/ 82. London: RCGP/HMSO, 1986.

20 Caldwell, Glanville unpublished data. In: Franks A. Low back pain. BMf 1993;306:901-9.

21 Biering Sorenson F. A prospective study of low back pain in a general population. I - occurrence, recurrence and in a general population. I - occurrence, recurre

22 Nachemson A. Work for all: for those with low back pain as well. Clin Orthop 1983;179:77-85.

23 Helliwell PS. Occupational rheumatology: are we using the wrong model? Brit $\mathcal{F}$ Rheumatol 1992;31:73-6.

24 Helliwell PS, Wright V. Referrals to rheumatology. BMF 1991;303:304-5. 